\title{
Contribution of rs1799998 polymorphism in CYP11B2 gene in susceptibility to preeclampsia
}

\section{Kaio Raffael Valotta Bezerra 1}

https://orcid.org/0000-0002-1301-3148

Sarah Cristina Sato Vaz Tanaka 2

https://orcid.org/0000-0003-4466-6093

Vanessa Resende Souza Silva 3

https://orcid.org/0000-0002-8313-5271

Marina Carvalho Paschoinni 4

https://orcid.org/0000-0003-2218-4747
Roseane Lopes da Silva Grecco 5

(iD) https://orcid.org/0000-0002-9823-2074

Fernanda Caroline Soardi 6

(iD) https://orcid.org/0000-0001-7801-2974

Marly Aparecida Spadotto Balarin 7

(iD) https://orcid.org/0000-0002-7535-0609

1,3-7 Departamento de Patologia, Genética e Evolução. Universidade Federal do Triângulo Mineiro. Uberaba, MG, Brasil.

2 Programa de Pós-graduação em Ciências da Saúde. Departamento de Patologia, Genética e Evolução. Universidade Federal do Triângulo Mineiro. Praça Manoel Terra, 330. Centro. Uberaba, MG, Brasil. CEP: 38.015-050. E-mail: sarahtanaka20@hotmail.com

\begin{abstract}
Objectives: the present study aimed to evaluate the association between the rs 1799998 polymorphism of the CYP11B2 gene and the susceptibility to preeclampsia (PE) in a Brazilian population.

Methods: the study group comprised 61 women who were diagnosed with PE. The control group included 116 women who did not show changes in their blood pressure levels during their pregnancies. The rs 1799998 polymorphism of the CYP11B2 gene was amplified by allele-specific polymerase chain reaction (PCR). A multiple logistic regression analysis was performed using the SNPStat program to evaluate the risk of the CYP11B2 gene rs 1799998 polymorphism contributing to $P E$.

Results: the PE group had the following genotypes: $1.64 \%$ CC, $91.80 \%$ CT, and $6.56 \%$ TT. In the control group, the observed genotypic frequencies were: $11 \%$ CC, $73 \%$ CT, and $16 \%$ TT. The genotypic frequency distribution did not fit the Hardy Weinberg Equilibrium (HWE) in either study group. The multiple logistic regression analysis showed a statistically significant difference for the rs 1799998 polymorphism in the recessive model.

Conclusion: the results suggest an association between the recessive model of $C / C$ genotype of the rs 1799998 polymorphism of the CYP11B2 gene and susceptibility to PE.

Key words Genetic Polymorphism, Preeclampsia, Cytochrome P-450
\end{abstract}

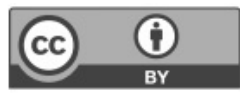




\section{Introduction}

Preeclampsia (PE) is defined as the presence of hypertension after the twentieth week of pregnancy, along with proteinuria or other findings, such as thrombocytopenia, renal failure, elevated transaminases, pulmonary edema, and focal and visual neurological changes. ${ }^{1,2}$ It affects about $5 \%$ of the pregnancies worldwide and is the primary cause of premature births in Brazil. ${ }^{3}$

Despite its severity, the pathogenesis of $\mathrm{PE}$ is not well understood, since it is a multifactorial disease. Diabetes, multiple pregnancy, nulliparity, obesity, maternal age over 40 years, kidney disease, chronic arterial hypertension, an interval greater than ten years since the last pregnancy, and personal or family history of PE are considered as risk factors for the development of the disease.4,5

Several genes have been linked to the development of PE, including genes that encode the proteins of the renin-angiotensin-aldosterone system (RAAS), as the Cytochrome P450 Family 11 Subfamily B Member 2 (CYP11B2) gene.6-8 This gene encodes a member of the cytochrome P450 enzyme superfamily, which has steroidal 18-hydroxylase activity to synthesize aldosterone. Haplotypes in this gene have been associated with a rare Mendelian form of hypertension, aldosteronism, which is remedied by glucocorticoids. One of the most studied polymorphisms is the single nucleotide polymorphism (SNP) rs1799998, located in the promoter region of the gene, position 344 , where there is an exchange of cytosine for thymine. 9,10 This SNP and its association with the development of PE have been studied previously. 11 Thus, the present work aimed to evaluate the association between the rs1799998 polymorphism of the CYP11B2 gene and the susceptibility to $\mathrm{PE}$ in a sample of the Brazilian population.

\section{Methods}

This study was approved by the Research Ethics Committee of the Federal University of Triângulo Mineiro (CEP / UFTM n ${ }^{\circ} 1115-08$ ), and all participants signed the Free and Informed Consent Form. The study group comprised 61 women over 18 years of age (mean age $28.7 \pm 8.3$ years), diagnosed with $\mathrm{PE}$, according to the criteria established by the American College of Obstetricians and Gynecologists (ACOG) in 2013.2 The control group comprised 116 women over the age of 18 years (mean age of $40.3 \pm 11.8$ years) who did not have changes in their blood pressure during their pregnan- cies. All participants were recruited at the Gynecology and Obstetrics Service of the Teaching Hospital of UFTM (Federal University of Triangulo Mineiro). Women with a history of chronic diseases were excluded from the study. Clinical information was obtained through interviews and reviews of medical records.

Genomic DNA was isolated from $8 \mathrm{~mL}$ of peripheral blood collected by venipuncture, in a vacuum and sterile tubes (BD Vacutainer $\left.{ }^{\circledR}\right)$, with EDTA, using the phenol-chloroform technique described by Sambrook. ${ }^{12}$ The rs 1799998 polymorphism of the CYP11B2 gene was amplified by allelespecific polymerase chain reaction (AS PCR) using the following primers: CYP11B2-344C: F-5'TTAAAAGAATCCAAGGCT-3“; CYP11B2-344T: F-5'-TTAAAAGAATCCAAGGCC-3' and CYP11B2 Ex1: R-5'-AGGTGCAGGTGCTCATAA3'. PCR was performed using $200 \mathrm{ng}$ of DNA $(1 \mu \mathrm{L})$, 20 pmol of each primer $(1 \mu \mathrm{L}), 10 \mathrm{X}$ buffer $(3 \mu \mathrm{L})$ (Invitrogen ${ }^{\mathrm{TM}}$, Carlsbad, California, USA), 5U Taq DNA polymerase $(0.2 \mu \mathrm{L}), 2 \mathrm{mM}$ dNTP $(2 \mu \mathrm{L}), 50 \mathrm{mM}$ $\operatorname{MgCl} 2(2 \mu \mathrm{L})$, and ultrapure water for a final volume of $30 \mu \mathrm{L}$. Amplification was performed on the Mastercycler ${ }^{\circledR}$ thermocycler (Eppendorf, Hamburg, Germany) under the following conditions: denaturation at $94^{\circ} \mathrm{C}$ for 5 minutes, 35 amplification cycles $\left(94^{\circ} \mathrm{C}\right.$ for 30 seconds, $60^{\circ} \mathrm{C}$ for 30 seconds, $72^{\circ} \mathrm{C}$ for 30 seconds), and the final extension at $72^{\circ} \mathrm{C}$ for 10 minutes. The PCR product was electrophoresed on a $2 \%$ agarose gel, stained with GelRed ${ }^{\circledR}$, allowing for the visualization of a 558-bp band. The images were acquired by the image capture system, L-PIX ${ }^{\circledR}$.

The risk assessment of the rs1799998 polymorphism of the CYP11B2 gene contributing to PE was conducted with a multiple logistic regression analysis performed using the SNPStats program (available at http://bioinfo.iconcologia.net/ SNPstats_web). In this analysis, the following inheritance models were used: codominant (wild homozygous $\times$ heterozygous $\times$ polymorphic homozygous), dominant (wild homozygous $x$ heterozygous + polymorphic homozygous), and recessive (polymorphic homozygous $\times$ wild homozygous + heterozygous). The SNPStats program was also used to verify whether the genotypic frequency in the groups was aligned with the Hardy Weinberg's Equilibrium (HWE). The results were presented as odds ratios (OR), with a $95 \%$ confidence interval (CI). The statistical power presented at $95.5 \%$ for the detection of an association. The G POWER 3.1 software was used for analysis. Statistical significance was defined as $p<0,05$. 


\section{Results}

177 samples were analyzed that included 61 samples with PE and 116 controls. In the PE group, 1.64\% (1/61) had the CC genotype, 91.80\% (56/61) had the CT genotype, and $6.56 \%(4 / 61)$ had the TT genotype. In the control group, the genotypic frequencies were $11 \%(13 / 116), 73 \%(85 / 116)$, and $16 \%(18 / 116)$ for the CC, CT and TT genotypes, respectively. The allele frequencies were 0.48 and 0.52 for the $\mathrm{C}$ and $\mathrm{T}$ alleles, respectively, in both groups. The distribution of the genotypic frequency was not in HWE in any of the studied groups (PE: $\chi^{2}=43.09, p<0.001$; $\left.\mathrm{C}: \chi^{2}=25.43, p<0.001\right)$.

The multiple logistic regression analysis showed a statistically significant difference for the rs 1799998 polymorphism in the recessive model $(p=0.0075)$ (Table 1).

\section{Discussion}

$\mathrm{PE}$ is a condition exclusive to human pregnancies and of great importance for medical practice. $13 \mathrm{~A}$ genetic component linked to its etiology has been demonstrated previously, where daughters of women who developed PE in their pregnancies had twice the risk of developing the disease than pregnant women without a family history. The same study demonstrated that severe PE was more strongly related to heredity, thereby strengthening the genetic aspects of both susceptibility to PE and its severity. 4

RAAS maintains plasma sodium concentration, blood pressure, and extracellular volume. An imbalance in this system can result in several pathologies, such as obesity, diabetes, and hypertension. ${ }^{14}$

The contribution of the rs1799998 polymor- phism of the CYP11B2 gene to the regulation of blood pressure has already been investigated in different populations, not related to preeclampsia. However, the results of these studies are controversial as they differ for ethnicity and other sociodemographic variables. ${ }^{15-17}$

In this study, the recessive model of the rs1799998 polymorphism of the CYP11B2 gene was associated with greater susceptibility to $\mathrm{PE}$, suggesting that being homozygous for the $\mathrm{C}$ allele conferred the risk for the development of the disease. However, Vasconcelos et al.18 evaluated 303 Brazilian women, of whom 118 were healthy pregnant women, 115 had gestational arterial hypertension, and 70 were diagnosed with PE, and did not observe a relationship between the CYP11B2 rs1799998 SNP and gestational hypertensive syndromes.

A study in South Africa, involving 200 pregnant women with early-onset PE, 200 with late-onset PE, and 200 normotensive pregnant women, with or without infection with the human immunodeficiency virus (HIV), investigated the rs 1799998 polymorphism of the CYP11B2 gene and found no association between this variant and susceptibility to PE. However, the frequency of the $\mathrm{C}$ allele was higher in the group of pregnant women with late PE without HIV than that in the control group. 6

Ramírez-Salazar et al. 19 evaluated the role of the rs 1799998 polymorphism of the CYP11B2 gene in blood pressure and circulating aldosterone levels in pregnant women. They observed only a marginal trend towards lower blood pressure levels in women with the TT genotype in normotensive pregnant women and no associations between the investigated genotypes and circulating aldosterone levels.

Table 1

\begin{tabular}{|c|c|c|c|c|c|c|c|}
\hline \multirow[t]{2}{*}{ Model } & \multirow[t]{2}{*}{ Genotype } & \multicolumn{2}{|c|}{$\mathrm{PE}(\mathrm{N}=61)$} & \multicolumn{2}{|c|}{ Control $(\mathrm{N}=116)$} & \multirow[t]{2}{*}{ OR (CI95\%) } & \multirow[t]{2}{*}{$p$} \\
\hline & & $\mathrm{n}$ & $\%$ & $\mathrm{n}$ & $\%$ & & \\
\hline & $\mathrm{T} / \mathrm{T}$ & 4 & 6.6 & 18 & 15.5 & 1.00 & \\
\hline \multirow[t]{2}{*}{ Codominance } & $\mathrm{C} / \mathrm{T}$ & 56 & 91.8 & 85 & 73.3 & $0.35(0.11-1.09)$ & 0.0041 \\
\hline & $\mathrm{C} / \mathrm{C}$ & 1 & 1.6 & 13 & 11.2 & $3.42(0.33-35.29)$ & \\
\hline \multirow[t]{2}{*}{ Dominance } & $\mathrm{T} / \mathrm{T}$ & 4 & 6.6 & 18 & 15.5 & 1.00 & \\
\hline & $\mathrm{C} / \mathrm{T}-\mathrm{C} / \mathrm{C}$ & 57 & 93.4 & 98 & 84.5 & $0.39(0.13-1.23)$ & 0.08 \\
\hline \multirow[t]{2}{*}{ Recessive } & $\mathrm{T} / \mathrm{T}-\mathrm{C} / \mathrm{T}$ & 60 & 98.4 & 103 & 88.8 & 1.00 & \\
\hline & $\mathrm{C} / \mathrm{C}$ & 1 & 1.6 & 13 & 11.2 & $8.83(1.09-71.29)$ & 0.0075 \\
\hline
\end{tabular}

$\mathrm{OR}=$ odds ratio; Multiple Logistic Regression. 
However, high levels of aldosterone have been associated with lower maternal blood pressure, and gainof-function $C Y P 11 B 2$ gene variants appear to reduce the risk of developing PE. 20

A study carried out in Poland with 59 pregnant women diagnosed with PE and 109 controls found no association between the polymorphism rs 1799998 of the CYP11B2 gene and PE but found the TT genotype with greater frequency in the study group than that in the normotensive pregnant women. ${ }^{11}$

In addition to genetic polymorphisms, epigenetic changes in the CYP11B2 gene may be responsible for interindividual and inter-ethnic variations in disease susceptibility. ${ }^{21}$ Significantly greater expression of miRNA-4421, a regulator of the CYP11B2 gene, has already been observed in the placenta of women with PE and is associated with elevated blood pressure, presence of proteinuria, and low birth weight. The hyperexpression of miRNA-4421 negatively regulates the expression of the CYP11B2 gene, which inhibits trophoblastic proliferation and blocks the cell cycle. This suggests that other regulatory mechanisms are involved in the gene expression that contributes to the development of PE, which should be considered. 22

In this study, both the control group and the study group were not in HWE. HWE depends on several assumptions, including simple Mendelian inheritance in diploid organisms, random mating, infinite population, and absence of mutation, migration, or selection. In addition to breaking these assumptions, failure to observe an HWE can be caused by genotyping error, which can lead to falsepositive results in genetic association studies and by non-random sampling. 23,24

In a truly random sample, each individual in the population has an equal opportunity to be sampled, which is virtually impossible to achieve in any real situation. This bias is minimized through heterozygous individuals, as they are more or less likely to be sampled than might be due to random chance. 25,26 In this study, this sampling bias does not appear to occur, given the high frequency of heterozygotes in both groups. Failure to observe the HWE in our sample suggests that the assumptions that maintain the HWE are not being followed, thereby influencing how the alleles are distributed over generations. However, it is not possible to identify which assumptions are being violated.

One of the limitations of this study is our patient sample size. However, the selected samples included women with PE and without other comorbidities, thus ensuring the homogeneity of the data. Future studies with a larger sample size, in collaboration with other research centers, are necessary to expand the knowledge of the molecular aspects of the etiology of PE. Also, studies that carry out the joint investigation of other RAAS polymorphisms in a larger number of patients and the influence of possible environmental factors are needed to validate our data and to determine if the rs 1799998 polymorphism of the CYP11B2 gene can, in the future, be used as a molecular marker capable of early detection of PE susceptibility.

In conclusion, this work suggests an association between the recessive $\mathrm{C} / \mathrm{C}$ genotype of the rs1799998 polymorphism of the CYP11B2 gene and susceptibility to PE.

\section{Acknowledgment}

We thank the Research Support Foundation of the State of Minas Gerais (FAPEMIG - Portuguese acronym) for the financial support.

\section{Authors' contribution}

Bezerra KRV contributed to data acquisition, laboratory analysis and writing of the manuscript. Tanaka SCSV contributed to data acquisition, analysis and interpretation of data and writing of the manuscript. Silva VRS e Paschoinni MC performed acquisition, laboratory analysis and writing of the manuscript. Silva-Grecco RL contributed to the conception and design of the study and critical review of the manuscript. Soardi FC carried out the conception and design of the study, analysis and interpretation of data; critical review of the manuscript. Balarin MAS participated in the conception and design of the study, analysis and interpretation of data, critical review of the manuscript; Project coordination. All authors approved the final version of the article. 


\section{References}

1. Phipps EA, Thadhani R, Benzing T, Karumanchi SA. Preeclampsia: pathogenesis, novel diagnostics and therapies. Nat Rev Nephrol. 2019; 15 (5): 275-89.

2. American College of Obstetricians and Gynecologists, Task Force on Hypertension in Pregnancy. Hypertension in pregnancy. Report of the American College of Obstetricians and Gynecologists' task force on hypertension in pregnancy. Obstet Gynecol. 2013; 122 (5): 1122-31.

3. Ramos JGL, Sass N, Costa SHM. Preeclampsia. Rev Bras Ginecol Obstet. 2017; 39 (9): 496-512.

4. Ayorinde AA, Bhattacharya S. Inherited predisposition to preeclampsia: Analysis of the Aberdeen intergenerational cohort.Pregnancy Hypertens. 2017; 8: 37-41.

5. Duckitt K, Harrington D. Risk factors for pre-eclampsia at antenatal booking: systematic review of controlled studies. BMJ. 2005; 12; 330 (7491): 565

6. Aung M, Konoshita T, Moodley J, Gathiram P. Association of gene polymorphisms of aldosterone synthase and angiotensin converting enzyme in pre-eclamptic South African Black women. Pregnancy Hypertens. 2018; 11: 3843.

7. Li X, Tan H, Zhou S, Hu S, Zhang T, Li Y, Dou Q, Lai Z, Chen F. Renin-angiotensin-aldosterone system gene polymorphisms in gestational hypertension and preeclampsia: a case-control gene-association study. Sci Rep. 2016; 2; 6: 38030 .

8. Devendran A, Nampoothiri S, Shewade DG, Chatterjee S, Jayaraman B, Chandrasekharan A. Allele, Genotype and Haplotype Structures of Functional Polymorphic Variants in Endothelial Nitric Oxide Synthase (eNOS), Angiotensinogen (ACE) and Aldosterone Synthase (CYP11B2) Genes in Healthy Pregnant Women of Indian Ethnicity. J Reprod Infertil. 2015; 16 (4): 180-92.

9. Connell JM, Fraser R, MacKenzie SM, Friel EC, Ingram MC, Holloway CD, Davies E. The impact of polymorphisms in the gene encoding aldosterone synthase (CYP11B2) on steroid synthesis and blood pressure regulation. Mol Cell Endocrinol. 2004; 217 (1-2): 243-7.

10. White PC, Slutsker L. Haplotype analysis of CYP11B2.Endocr Res. 1995; 21 (1-2): 437-42.

11. Bogacz A, Bartkowiak-Wieczorek J, Procyk D, SeremakMrozikiewicz A, Majchrzycki M, Dziekan K, Bienert A, Czerny B. Analysis of the gene polymorphism of aldosterone synthase (CYP11B2) and atrial natriuretic peptide (ANP) in women with preeclampsia. Eur J Obstet Gynecol Reprod Biol. 2016; 197: 11-5.

12. Sambrook J, Fritsch EF, Maniatis TE. Molecular cloning, a laboratory manual. 2 ed. New York: Cold Spring Harbor Laboratory Press; 1989.

13. Ota E, Ganchimeg T, Morisaki N, Vogel JP, Pileggi C, Ortiz-Panozo E, Souza JP, Mori R; WHO Multi-Country Survey on Maternal and Newborn Health Research Network. Risk factors and adverse perinatal outcomes

Received on September 18, 2019

Final version presented on January 30, 2020

Approved on February 28, 2020 among term and preterm infants born small-for-gestationalage: secondary analyses of the WHO Multi-Country Survey on Maternal and Newborn Health. PLoS One. 2014; 13; 9 (8): e105155.

14. Patel S, Rauf A, Khan H, Abu-Izneid T. Renin-angiotensinaldosterone (RAAS): The ubiquitous system for homeostasis and pathologies. Biomed Pharmacother. 2017; 94: 317-325.

15. Munshi A, Sharma V, Kaul S, Rajeshwar K, Babu MS, Shafi G, Anila AN, Balakrishna N, Alladi S, Jyothy A. Association of the $-344 \mathrm{C} / \mathrm{T}$ aldosterone synthase (CYP11B2) gene variant with hypertension and stroke. J Neurol Sci. 2010; 15; 296 (1-2): 34-8.

16. Sousa AC, Reis RP, Pereira A, Borges S, Freitas AI, Guerra G, Gouveia S, Góis T, Nóbrega L, Rodrigues M, Henriques E, Freitas S, Ornelas I, Pereira D, Brehm A, Mendonça MI. Genetic Polymorphisms Associated with the Onset of Arterial Hypertension in a Portuguese Population. Acta Med Port. 2018; 31 (10): 542-50.

17. Wang L, Zhang B, Li M, Li C, Liu J, Liu Y, Wang Z, Zhou $\mathrm{J}$, Wen S. Association between single-nucleotide polymorphisms in six hypertensive candidate genes and hypertension among northern Han Chinese individuals. Hypertens Res. 2014; 37 (12): 1068-74.

18. Vasconcelos D, Izidoro-Toledo TC, Sandrim VC, TanusSantos JE, Palei AC, Cavalli RC. Aldosterone synthase gene polymorphism is not associated with gestational hypertension or preeclampsia. Clin Chim Acta. 2009; 400 (1-2): 139-41.

19. Ramírez-Salazar M, Romero-Gutiérrez G, Zaina S, Malacara JM, Kornhauser C, Pérez-Luque E. Relationship of aldosterone synthase gene (C-344T) and mineralocorticoid receptor (S810L) polymorphisms with gestational hypertension. J Hum Hypertens. 2011; 25 (5): 320-6.

20. Escher G, Cristiano M, Causevic M, Baumann M, Frey FJ, Surbek D, Mohaupt MG. High aldosterone-to-renin variants of CYP11B2 and pregnancy outcome. Nephrol Dial Transplant. 2009; 24 (6): 1870-5.

21. Manikandan P, Nagini S. Cytochrome P450 Structure, Function and Clinical Significance: A Review. Curr Drug Targets. 2018; 19 (1): 38-54

22. Gao X, Li H, Wei JX. MiR-4421 regulates the progression of preeclampsia by regulating CYP11B2. Eur Rev Med Pharmacol Sci. 2018; 22 (6): 1533-40.

23. MCcarthy, MI, Abecasis, GR, Cardon, LR, Goldstein, DB, Little, J, Ioannidis, JP, Hirschhorn JN. Genome-wide association studies for complex traits: consensus, uncertainty and challenges. Nat Rev Genet. 2008; 9: 356-69.

24. Mitchell, AA, Cutler, DJ, Chakravarti, A. Undetected genotyping errors cause apparent over transmission of common alleles in the transmission/disequilibrium test. Am J Hum Genet. 2003; 72: 598-610.

25. Jankovic I, vonHoldt BM, Rosenberg NA. Heterozygosity of the Yellowstone wolves. Mol Ecol. 2010; 19: 3246-49.

26. Waples RS. Testing for Hardy-Weinberg proportions: have we lost the plot? J Hered. 2015; 106: 1-19. 